\title{
The Forensic Psychology Role: Technical Advisor Office ${ }^{\dagger}$
}

\author{
Iris Almeida ${ }^{1,2,3, * \mathbb{D}}$, Ana Ramalho ${ }^{3}$, Joana Costa ${ }^{3}$ and Ricardo Ventura Baúto ${ }^{1,2,3} \mathbb{D}$ \\ 1 Instituto Universitário Egas Moniz (IUEM), Egas Moniz-Cooperativa de Ensino Superior, Crl., \\ 2829-511 Almada, Portugal; rbauto.lcfpem@egasmoniz.edu.pt \\ 2 Laboratório de Psicologia (LabPSI), Centro de Investigação Interdisciplinar Egas Moniz (CiiEM), \\ 2829-511 Almada, Portugal \\ 3 Laboratório de Ciências Forenses e Psicológicas Egas Moniz (LCFPEM), 2829-511 Almada, Portugal; \\ acnramalho@gmail.com (A.R.); jcosta.lcfpem@egasmoniz.edu.pt (J.C.) \\ * Correspondence: ialmeida@egasmoniz.edu.pt \\ + Presented at the 5th International Congress of CiiEM-Reducing inequalities in Health and Society, Online, \\ 16-18 June 2021.
}

\begin{abstract}
The purpose of this paper is to demonstrate the work developed by Technical Advisor Office (GAT) and its role as technical advisor to the West Lisbon Public Prosecutor's Office. GAT was established in partnership with Egas Moniz Higher Education School and West Lisbon Public Prosecutor's Office. GAT plays a crucial role in assisting the Public Prosecutor's Office as the main response to cases with higher complexity, and it provides support about measures to protect victims. GAT integrates the forensic psychologist narrowly and directly in monitoring processes in the judicial system, allowing a greater understanding of the phenomenon and facilitating decision-making by the Public Prosecutor's Office.
\end{abstract}

Keywords: forensic psychology; technical advisor; public prosecutor's office

check for updates

Citation: Almeida, I.; Ramalho, A.; Costa, J.; Baúto, R.V. The Forensic Psychology Role: Technical Advisor Office. Med. Sci. Forum 2021, 5, 13. https://doi.org/10.3390/msf 2021005013

Academic Editors: Helena Barroso and Cidália Castro

Published: 20 July 2021

Publisher's Note: MDPI stays neutral with regard to jurisdictional claims in published maps and institutional affiliations.

Copyright: (c) 2021 by the authors. Licensee MDPI, Basel, Switzerland. This article is an open access article distributed under the terms and conditions of the Creative Commons Attribution (CC BY) license (https:// creativecommons.org/licenses/by/ $4.0 /)$.

\section{Introduction}

The relevance of psychology in the Portuguese Justice System has been gaining projection in recent decades, emerging from the articulation between the two areas of knowledge, Forensic Psychology as a scientific discipline and with scope to allow its specialization [1,2]. Considering that the object of Forensic Psychology is the evaluation of human behaviour associated with the different contexts of justice's action and except for the importance that it has been acquiring at the level of the investigation phase, the presence of the psychologist in the justice system is configured as a technical element, capable of assisting in the intervention processes associated with victims, offenders, magistrates or other judicial officials. The evolution of criminal and procedural legislation has highlighted the role of psychological sciences as an asset in different areas of judicial decision. To note that the role of Forensic Psychology has been the most pertinence in the investigation phases as a tool to aid judicial decision, verifying through statistical analyses promoted in several studies [3]. That expert reports drawn up by forensic psychologists are mostly welcomed by the magistrates [1]. More recently, with legislative and regulatory reforms, new competencies and dynamics of intervention and prevention of forensic psychologists have emerged. In this sense, the forensic psychologist appears in this institution with the function of fulfilling the needs evoked by the justice system itself, seeking under its specific competencies to respond to the needs evidenced in this context. Thus, the Technical Advisor Office gives an integrated and direct response by inserting the forensic psychologist in the justice system, allowing a faster speed in the decision-making processes that result from the action of the Public Prosecutor's Office. 


\section{Materials and Methods}

In 2019 and 2020, GAT had intervention in 231 criminal cases in West Lisbon Public Prosecutor's Office. Data was collected from lawsuits, semi-structured interviews of the victims and defendants, collateral information, and clinical and forensic assessment tools. All ethical issues have been taken due to the sensitive nature of the detailed data and the respective informed consentient, the confidentiality limits, and information about the ethics and technician's impartiality.

\section{Results and Discussion}

In 2019, it was possible to verify that 96 interventions were carried out with victims of crime (74 women and 22 men). In 2020, it was possible to verify that 201 interventions were carried out with victims of crime (128 women and 73 men). Article 271 of the Portuguese Code of Criminal Procedure allows the prosecutors and the inquiring judge to record the victim's testimony and use it during the future trial. This procedure, called future memory statements, prevents the victim from being exposed months or years later to the memories of a traumatic event. To minimize this, it is necessary to inform and prepare the victims for this diligence, explaining the court procedures. In 2019, to follow-ups in procedural acts, it was found that 33 occurred in future memory statements, and 26 other acts (e.g., monitoring of victims in recognition of suspects; making statements by prosecutors). In forensic psychological assessment: 19 psychological assessments; 7 forensic psychological assessment (with subsequent follow-up in future memory statements); 6 domestic violence risk assessments; 5 domestic violence risk assessments (with subsequent follow-up in future memory statements). In 2020, 86 psychological assessments; 16 forensic psychological evaluations with subsequent follow-up in procedural acts (future memory statements, inquiry, trial hearing and parent conferences); and two violence risk assessments. Follow-up in procedural acts found that 28 due diligence took place (e.g., making statements by prosecutors) and 26 future memory statements. GAT seeks to be an asset in straightforward advice to the justice system, having its main premise, the action close to the victim, with active support in judicial decision making. The demand for services provided in the superior support of victims of crime is the fundamental basis of GAT.

Institutional Review Board Statement: This study is part of a protocol established among the Portuguese Public Prosecutor's Office and Egas Moniz-Higher Education School to assess and analyze the characteristics of victims and offenders in the field of Violence. The strictness of ethical and deontological principles is safeguarded once criminal records have been restricted access by law (including judicial secrecy). Therefore, all assessed subjects gave their informed consent, and their data were processed anonymously.

Informed Consent Statement: All ethical issues were considered due to the sensitive nature of the detailed data, the respective informed consent, confidentiality limits, and information about the ethics and technician's impartiality.

Data Availability Statement: Data sharing not applicable because part of information derives from criminal records.

Conflicts of Interest: The authors declare no conflict of interest.

\section{References}

1. Gonçalves, R.A. Psicologia forense em Portugal: Uma história de responsabilidades e desafios. Anál. Psicol. 2010, 28, 107-115. [CrossRef]

2. Matos, M.; Gonçalves, R.A.; Machado, C. Manual de Psicologia Forense: Contextos, Práticas e Desafios; Coords: Psiquilíbrios, Portugal, 2011.

3. Castro, A.J.; Martins, A.S.; Machado, C.; Gonçalves, R.A. Perícias Psicológicas, Sentenças Judiciais: Que Relação? Poster Apresentado no Congresso Internacional de Psicologia Forense; Universidade do Minho: Braga, Portugal, 2006. 